\title{
Estimating the Fertility Level of Registered Indians in Canada: A Challenging Endeavour
}

\author{
Shirley Loh \\ M. V. George \\ Demography Division \\ Statistics Canada \\ Ottawa, Ontario, Canada
}

\begin{abstract}
The Indian Register is the most comprehensive source of fertility data pertaining to Registered Indians. A reasonable time series for the births and population under question can be derived. However, it is well known that registration of births in the Register suffers from data limitations. The purpose of this paper is to discuss the methodologies used to adjust time series data on births and procedures used to derive accurate estimates of fertility, namely total fertility rates. The impact of the 1985 amendments to the Indian Act on deriving accurate fertility rates for Registered Indians is also addressed in the paper.
\end{abstract}

Key Words: Registered Indians, Indian Register, fertility. 
Shirley Loh \& M. V. George

\section{Résumé}

Le registre des Indiens est la source de données la plus complète au sujet de la fécondité des Indiens inscrits. On peut en extraire des séries chronologiques acceptables de naissances et d'effectifs de population. Cependant, il est bien connu que l'enregistrement des naissances au registre est déficient. L'objectif de cet article est de discuter des méthodes utilisées pour rajuster les séries chronologiques des naissances et, des procédures pour en dériver des estimations précises de la fécondité, c'est-à-dire des indices synthétiques de fécondité. On y discute également de l'impact sur la mesure de taux de fécondité précis des amendements de 1985 à la Loi sur les Indiens.

Mots-clés: Indiens, le registre des Indiens, fécondité.

\section{Introduction}

Research on the fertility level of Registered Indians in Canada is sparse mainly due to lack of reliable data. In general, there are three major sources of data: (i) census of Canada; (ii) Health Canada Medical Services Branch data; and (iii) the Indian Register maintained by the Department of Indian Affairs and Northern Development (DIAND). Among these sources, the data from the censuses of Canada, and the Indian Register are the most widely used. Romaniuc (1993, $1992,1987)$ used data from the 1961, 1971 and 1981 censuses to describe the fertility transition of Canadian aboriginals, with separate discussions on the native Indians. These papers also provide a discussion of fertility differentials by the main aboriginal groups: status Indians ${ }^{1}$, non-status Indians, Métis and Inuits; by type of residence (rural-urban) for native Indian women; by level of education for status Indian women; and by socio-economic indicators ${ }^{2}$ for native and non-native women. Romaniuc (1992) provides an explanatory framework, which includes the modernization theory and the distinctive features of the aboriginal society to explore the underlying processes involved in the fertility transition.

Also, using census data, Ram (1991) examines the impact of assimilation on native fertility in relation to the lack of convergence between the native Indian and overall Canadian childbearing patterns in the 1980s. Though census data are widely used to study the fertility patterns of native Indians, "data for native Indians may not be strictly comparable from one census to another because of conceptual and coverage problems" (Ram, 1991). Moreover, census fertility 
data refer to ever-married women only, which do not provide a complete picture of fertility for the native Indian population, as a large proportion of native Indian children are born out-of wedlock (Ram and Romaniuc, 1985).

Generally speaking, the data from the Health Canada Medical Services Branch are subject to two limitations. First, the data pertain to status Indians living on reserve only. Second, there is a lack of consistency in the collection procedures among provinces (Ram and Romaniuc, 1985). Data are collected through regional offices, zone offices, and a network of hospitals, nursing stations, health centres and various health facilities.

Data on births from the Indian Register maintained by DIAND have been analyzed extensively by Demography Division of Statistics Canada while preparing fertility projections as a component of projecting the population of Registered Indians (Loh et al, 1998, Nault et al, 1993, Loh, 1990, Perreault et al, 1985). DIAND uses the demographic data from the Indian Register for most of its planning and policy making purposes. These data, especially the data on births, are known to suffer from two major limitations: (i) late-reporting and (ii) underreporting of events. Further, in 1985, the amendments to the Indian Act, or Bill C-31 introduced a set of new descent rules, affecting entitlement to Indian status which have significant implications on the calculation of total fertility rate (TFR).

The purpose of this paper is to describe the methodological steps and procedures involved in correcting the data from the Indian Register and to derive accurate estimates of fertility level. The impact of the 1985 amendments to the Indian Act on deriving reliable total fertility rates for Registered Indians will also be addressed. The paper concludes with a discussion on the anticipated challenges that researchers have to overcome while attempting to estimate the fertility level of Registered Indians in Canada.

\section{Data Sources: The Indian Register}

The data for this paper are taken from the Indian Register maintained by the Department of Indian Affairs and Northern Development (DIAND). The Indian Register is similar to a continuous registration system. It offers a unique source of information on the Registered Indian population, and is used for collecting demographic statistics, such as births, deaths, marriages, etc. As the Register is established mainly for administrative rather than statistical purposes, and there are no legal obligations or incentives for registering events promptly, the data from the Register are subject to the two main data problems mentioned earlier, and other data anomalies. Thus, data from the Indian Register suffer from limitations that seriously distort the demographic indices directly calculated from them, e.g. total fertility rates. In order to establish reliable fertility rates, it 
was therefore, essential to adjust the data on the number of births and female population.

\section{Adjustment of Data on Births}

Evaluations of the data on births from the Indian Register show that in addition to the two major limitations, namely late reporting and underreporting of events, there are also other major data problems, such as coding inconsistencies, double counting, missing data, incomplete registration for an entire area and anomalies in reporting patterns (Loh, 1997a; Nault et al, 1992). The following discussions will address each of these problems.

\section{Coding Inconsistencies}

Coding inconsistencies occurred after the 1985 Bill C-31 amendments, which restored Indian status and membership rights to individuals (and their children) who had lost them because of discriminatory clauses contained in the previous Act. Between 1985 and 1989, the codes introduced into the Indian Register to identify reinstated Indians were not identical in the demographic reporting system where population data were compiled. As a result, some of the reinstated Indians were misclassified in the demographic system as part of the late reported births that occurred over the 1973 to 1985 period. These miscoded events had to be identified and removed as they artificially inflated the number of births that occurred during those years. This was accomplished by record linkage operations.

\section{Double Counting and Missing Data}

A marked increase in the number of births in 1983 and 1984 was attributed to double counting in all regions except the Northwest Territories and Atlantic region (Nault et al, 1992). This problem was corrected by linking the birth data file to the population data file. Conversely, irregularities in the data on births for the years 1974 and 1977 were the result of missing birth data in British Columbia. The missing data were recovered using archives data extracted at earlier dates.

\section{Incomplete Registration for an Entire Area}

No births were reported in the Northwest Territories in 1985. Since the Northwest Territories is a small region and the number of late reported births in the following years seemed to compensate for the missing births, this was treated as a part of the late reporting problem. 


\section{Anomaly in the Reporting Patterns}

There was a sudden drop in the number of births in 1991, from 14,400 in 1990 to 13,777 in 1991 and the number bounced back to 14,768 in 1992 . This decrease was noticeable in five out of the nine regions (Quebec, Ontario, Saskatchewan, Alberta and British Columbia). Since no adequate explanation could be found for the decline, it was considered as an anomaly and the 1991 figures were replaced by averages of 1990 and 1992 data for the five affected regions.

\section{Late Reporting}

A large proportion of Indian births are not reported to the Indian Register during the year in which they occur, but are reported several years later (Piché and George, 1973). Since births are classified by year of registration and year of occurrence, it is possible to measure the length of reporting delays. Table 1 shows the inconsistencies in population data resulting from the late reporting of births. A preliminary test of the accuracy of reported births is to compare reported births with the expected population. Since the Registered Indians are a closed population with no international migration, births and deaths are virtually the only factors in population change at ages 0 and 1, thus the number of survivors of birth cohorts should not exceed the initial number. Yet the data show that the number of survivors at age one is much larger than the initial number at age 0 in the previous year. For example, in 1996, the population aged 1 was 11,205 , which was more than double the population aged 0 in 1995, reported as 5,198 .

An examination of the time series data on births indicates that births continue to be reported up to 18 years after their occurrence. For example, births that occurred in 1973 could continue to be reported until 1991. The number of late reported births is largest in the first year following those births, then the number of late reported births diminishes in subsequent years. Most births are reported within 6 years of their occurrence, and the number reported after 18 years is negligible. The reallocation of late reported births to their actual year of occurrence is straightforward as the required distribution of births by year of occurrence and year of reporting is readily available. However, it is also necessary to estimate the number of not-yet-reported births, which have occurred but will not be reported until a later year.

Different approaches were used to estimate the not-yet-reported births as the appropriate method rests on past trends in the pattern of late reporting which can vary from one year to another. The approach used by Ram and Romaniuc (1985) and Loh (1990) was to extrapolate the actual number of births for each $\mathrm{lag}^{3}$, using the trend of the preceding 3, 4 or 5 years. This method was chosen 
Table 1

Late Reporting of Births and Its Impact on the Registered Indian Child Population for Canada, 1976 to 1996

\begin{tabular}{cccc}
\hline Year & $\begin{array}{c}\text { Population } \\
\text { Under Age 1 }\end{array}$ & $\begin{array}{c}\text { Population } \\
\text { Aged One Year }\end{array}$ & $\begin{array}{c}\text { Cohort } \\
\text { Increase }\end{array}$ \\
\hline $\mathbf{1 9 7 2}$ & 6,025 & -- & -- \\
$\mathbf{1 9 7 3}$ & 4,854 & 6,953 & 928 \\
$\mathbf{1 9 7 4}$ & 5,062 & 7,296 & 2,442 \\
$\mathbf{1 9 7 5}$ & 4,756 & 7,268 & 2,206 \\
$\mathbf{1 9 7 6}$ & 4,613 & 6,976 & 2,220 \\
$\mathbf{1 9 7 7}$ & 5,211 & 6,913 & 2,300 \\
$\mathbf{1 9 7 8}$ & 5,305 & 7,033 & 1,822 \\
$\mathbf{1 9 7 9}$ & 5,156 & 7,305 & 2,000 \\
$\mathbf{1 9 8 0}$ & 5,172 & 7,152 & 1,996 \\
$\mathbf{1 9 8 1}$ & 5,013 & 7,215 & 2,043 \\
$\mathbf{1 9 8 2}$ & 5,397 & 7,512 & 2,499 \\
$\mathbf{1 9 8 3}$ & 6,086 & 7,961 & 2,564 \\
$\mathbf{1 9 8 4}$ & 3,100 & 7,927 & 1,841 \\
$\mathbf{1 9 8 5}$ & 3,168 & 7,434 & 4,334 \\
$\mathbf{1 9 8 6}$ & 3,994 & 7,797 & 4,629 \\
$\mathbf{1 9 8 7}$ & 3,964 & 7,468 & 3,474 \\
$\mathbf{1 9 8 8}$ & 3,497 & 7,548 & 3,584 \\
$\mathbf{1 9 8 9}$ & 2,910 & 7,574 & 4,077 \\
$\mathbf{1 9 9 0}$ & 4,724 & 8,687 & 5,777 \\
$\mathbf{1 9 9 1}$ & 5,187 & 10,221 & 5,497 \\
$\mathbf{1 9 9 2}$ & 3,810 & 8,231 & 3,044 \\
$\mathbf{1 9 9 3}$ & 4,855 & 11,113 & 7,303 \\
$\mathbf{1 9 9 4}$ & 5,127 & 11,334 & 6,479 \\
$\mathbf{1 9 9 4}$ & 5,198 & 11,346 & 6,219 \\
$\mathbf{1 9 9 5}$ & -- & 11,205 & 6,007 \\
\hline & & & \\
\hline & & & \\
\hline & & & \\
\hline & & & \\
\hline
\end{tabular}

Source: Unadjusted data from the Indian Register (DIAND) 
for the following reasons. First, the most current changes in the pattern of late reporting could be accounted for by the method. Second, when compared with results obtained by adjusting the number of births for late reporting directly at the national level only, the results obtained by the two methods were very close. Third, the method yielded a fairly consistent trend over time for each lag.

A regression method applied to a lag of 5 years was used in two later studies (Nault et al, 1992; Loh et at, 1998). The procedure involved the following: First, the late reported births were cumulated by lag (i.e. lag 0-1, 0-2, 0-3, 0-4 and $0-5$ ) for each birth cohort. Second, the late reported births cumulated up to a certain lag, say $0-2$, were regressed on the births cumulated up to the previous lag, say lag $0-1$. In this way, the number of births that were estimated up to a certain lag was built upon the estimates from the previous lag. A regression method was done on the cumulated number of births, as the cumulated pattern is more stable than the non-cumulated pattern.

To estimate the births for lags 6 and onwards, Nault et al (1992) used the averages of the births over the 1972 to 1990 period in the model. However, in the most recent study, a different estimation procedure was used by Loh et al (1998) as there was a decline in the number of late reported births for lags 6 and higher in recent years. An extrapolated annual rate of change based on observed data for each lag was, therefore, used to estimate the number of not-yet-reported births for lags 6 to 18. It was assumed that the annual rate of change would diminish in the future and would reach 0 in 50 years.

\section{Underreporting}

This step was developed to take into account the cases where a baby dies before its birth is recorded in the Register. In these cases, the event is not reported as a birth or a death. Ram and Romaniuc (1985) used independently derived figures to evaluate the completeness of the adjusted number of births in order to estimate the extent of underreporting. They used the "reverse-survival method" to evaluate the extent of underreporting of Indian births. On the assumption that children currently at age $\mathrm{x}$ are survivors of the children born $\mathrm{x}$ years ago, this method "reverse-survives children at age $x$ enumerated in the census and compares them with the number of births that occurred x years ago" (Ram and Romaniuc, 1985). Thus the estimated number of births (B) is:

$$
\mathrm{B}={ }_{5} \mathrm{~N}_{0} /{ }_{5} \mathrm{~L}_{0}
$$

where ${ }_{5} \mathrm{~N}_{0}$ is the population in age group $0-4$ and ${ }_{5} \mathrm{~L}_{0}$ is the number of personyears lived between birth and exact age 5, obtained from an appropriate life table. 
The following steps were taken by Ram and Romaniuc (1985) to estimate the number of births by the "reverse-survival method" for the periods 1971-76 and 1976-81. First, the age and sex data for Registered Indians, as obtained from the 1981 Census, were adjusted for possible undercoverage (using the overall undercoverage rate for the age groups $0-4$ and 5-9), possible refusals and the institutionalized population, and other non-Indians who were enumerated as native Indians. This was done for both sexes and for every province. Second, the population aged 0-4 in 1981 was survived in reverse order based on the life tables for the total Canadian population in 1940-42, which were considered to approximate the current mortality patterns of the Registered Indians ${ }^{4}$. Third, the resulting figures provided estimates of the average number of births (B) for 1976-81. Fourth, births for the period 1971-76 were also estimated.

A comparison between the average number of births from the Indian Register and the estimated average number of births as derived by the "reverse-survival method" using census data for periods 1971-76 and 1976-81 shows that data on births from the Indian Register were affected by underreporting for most of the provinces in 1971-76, and for Quebec and Ontario only in 1976-81. The largest difference was in the latter period for Quebec, the underreporting of births was about 19 per cent.

They also compared the 1981 total fertility rates obtained from the Indian Register, with the own-children ratio calculated from the 1981 Census households and family data, and children ever-born per ever-married woman obtained from the 1981 Census fertility data. This comparison reinforced the findings of the "reverse-survival method" that data on births from the Indian Register might be underestimated for most of the provinces, and they were definitely underestimated for Quebec. Thus, they adjusted Quebec's fertility level for 1981, the base year of the projections.

Nault et al (1992) and Loh et al (1998) used the Brass model (Brass, 1968) to estimate the level of underreporting of births among the Registered Indians. This is a demographic procedure commonly used to smooth life table functions in situations where deaths are underreported at certain ages. Based on the linear relationship of the logits of the life table functions between the overall Canadian and the Registered Indian mortality, the Brass model produced a set of smoothed values of the life table for Registered Indians. The fit was close to perfect except for ages 0 and $65+$ where the model yielded higher mortality rates. The differences were partly attributed to problems of underreporting of deaths, and the observed values at these ages were replaced with values from the model. The difference between the estimated number of infant deaths based on infant mortality values from the model and the reported number of infant deaths from the Register (after the adjustments for late reporting) yielded the estimated number of underreported infant deaths, or underreported births. 


\section{Impact of Each Type of Adjustment on Time Series of Births}

Figure 1 shows the impact of each type of adjustment on the time series of births in Canada, from 1973 to $1996^{5}$. It can be seen that adjustments for not-yetreported births increased over time, thus adjustments for late reporting became more and more significant over the time period. It is worth noting that, starting in 1992, the adjustments for late reporting reversed the downward trend, since a significant proportion of the births that had occurred were not reported yet. Adjustments for not-yet-reported births were not necessary for the time series before 1979. Adjustments for not-yet-reported births, however, increased steadily over the years thereafter. For the years after 1992, more than 1,000 births had to be added to the time series per year in order to account for the births that had occurred but had not-yet been reported.

Figure 1 also shows that the adjustment for underreporting has a very limited impact on the annual number of births since the adjustment for underreporting is relatively small, around 100 births per year between 1973 and 1988, and approximately 85 per subsequent years. Hence, the difference between the lines showing "adjusted for late reporting" and "fully adjusted" is insignificant.

\section{Adjustment of Population Data}

In order to derive reliable fertility estimates of the Registered Indians, the population data were adjusted for both the late reporting and underreporting of births and deaths. Basically, the adjustment of population data involves the following steps. First, the late reported births have to be assigned to their year of occurrence, and the not-yet-reported births have to be estimated, then the cohorts must be "aged" through successive years. In other words, the birth cohort of year $t$ becomes the population of age 1 in year $t+1$, the population of age 2 the following year, and so on. Second, these births and the derived population were then added to the corresponding recorded population numbers from the Indian Register for the appropriate ages. Third, a similar adjustment was made for deaths except that the number of deceased individuals at each age was subtracted from the corresponding reported population number in the Register data.

\section{Estimating the Total Fertility Rate (TFR)}

From the Indian Register, the following data are available to derive the TFR: total number of reported births, distribution of these births by age of mother, and female population aged 15 to 49 . Since the adjustment of data on births was not done by age of mother, distributions of unadjusted births by age of mother from the Register were used to distribute total adjusted births by age of mother. 
Figure 1

Births by Type of Adjustment

for Registered Indians

Canada, 1973 to 1996

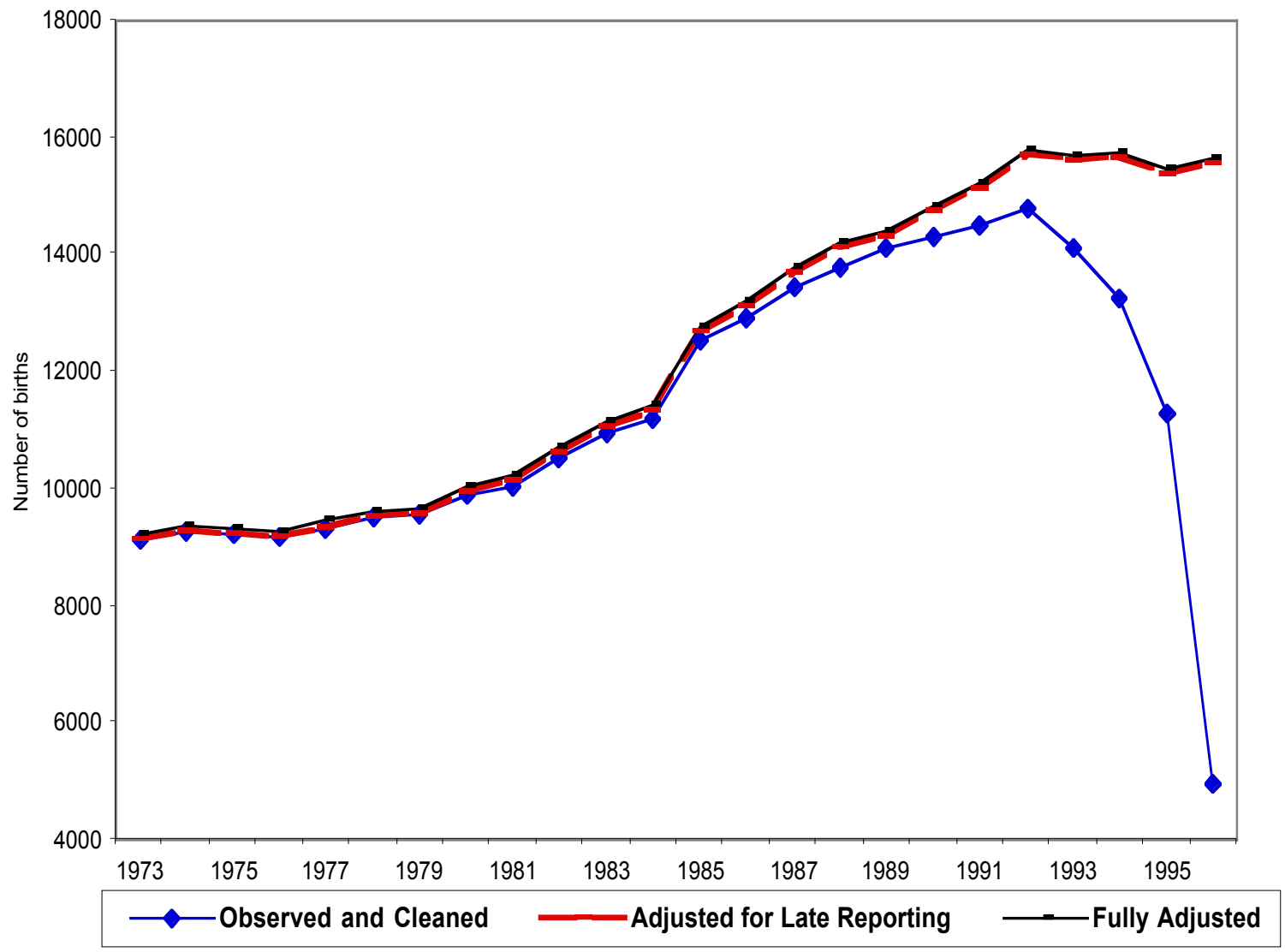




\section{Rules Governing Inheritance of Indian Status ${ }^{6}$ and their Impact on Calculating Fertility Rates}

The 1985 amendments to the Indian Act or Bill C-31 contain a set of descent rules, which establish entitlement to Indian status (Figure 2). These rules result in two groups of Registered Indians. The first group is entitled to register under Section 6(1) of the Act, the second group under Section 6(2). Children born to parents, both of whom are currently registered or entitled to be registered, acquire entitlement under Section 6(1). Children born to parent combinations

involving a parent registered or entitled to be registered under Section 6(1) and a non-Indian parent, acquire entitlement under Section 6(2). Offspring from parental combinations involving a non-Indian parent and a parent registered or entitled to be registered under Section 6(2) are not entitled to become Registered Indians.

The descent rules have important implications on the future size of the population eligible for registration and the way the TFR is derived. When developing fertility rates for Registered Indians, the problem of an incompatible numerator and denominator occurs under two circumstances: children of parental combinations of 6(1) Registered Indian males and non-Indian females are entitled to be registered but their mothers are not on the Register; and children of 6(2) Registered Indian females and non-Indian males are not entitled to be registered while their mothers are on the Register (Loh, 1997b). In order to obtain numerator and denominator consistency, the children born of 6(1) males and non-Indian females have to be excluded from the numerator and the out-married 6(2) females have to be removed from the denominator. In the following section, the methodology used to achieve a compatible numerator and denominator will be discussed in detail.

\section{Adjustment of Data for Achieving a Compatible Numerator and Denominator}

As mentioned earlier, in order to achieve numerator and denominator consistency, it is necessary to estimate the number of children belonging to parent combinations of 6(1) males and non-Indian females, and the number of $6(2)$ females who married non-Indians. Based on information on total number of births resulting from a relationship consisting of a 6(1) male and a non-Indian female for reporting years 1991 to 1996, a crude estimate of the number of children with 6(1) males and non-Indian females as parents was derived and these births were excluded from the numerator before generating the fertility rates for Registered Indians. 
Figure 2

Implications of Rules Governing Entitlement to Indian Registration under the 1985 Amendments to the Indian Act

\begin{tabular}{|c|c|c|c|}
\hline \multicolumn{2}{|c|}{ Parental Combination } & \multirow{2}{*}{ Status of Child } & \multirow{2}{*}{ Implications } \\
\hline Father & Mother & & \\
\hline 6(1) Indian & 6(1) Indian & 6(1) Indian & $\begin{array}{l}\text { Both mother and } \\
\text { child on Register }\end{array}$ \\
\hline 6(1) Indian & 6(2) Indian & 6(1) Indian & $\begin{array}{l}\text { Both mother and } \\
\text { child on Register }\end{array}$ \\
\hline 6(2) Indian & 6(1) Indian & 6(1) Indian & $\begin{array}{l}\text { Both mother and } \\
\text { child on Register }\end{array}$ \\
\hline 6(2) Indian & 6(2) Indian & 6(1) Indian & $\begin{array}{l}\text { Both mother and } \\
\text { child on Register }\end{array}$ \\
\hline Non Indian & 6(1) Indian & 6(2) Indian & $\begin{array}{l}\text { Both mother and } \\
\text { child on Register }\end{array}$ \\
\hline 6(1) Indian & Non Indian & $6(2)$ Indian & $\begin{array}{l}\text { Child on Register, } \\
\text { mother not on } \\
\text { Register }\end{array}$ \\
\hline Non Indian & 6(2) Indian & Non Indian & $\begin{array}{l}\text { Mother on } \\
\text { Register, child not } \\
\text { on Register }\end{array}$ \\
\hline 6(2) Indian & Non Indian & Non Indian & $\begin{array}{l}\text { Both mother and } \\
\text { child not on } \\
\text { Register }\end{array}$ \\
\hline
\end{tabular}

According to the inheritance rules, children of 6(2) Registered Indian females who married non-Indians are not entitled to be registered in the Indian Register. Thus, these 6(2) females who out-married had to be excluded from the denominator before calculating the fertility rates for Registered Indians. Consequently, the denominator or number of females by age used in developing the fertility rates refers to the female population corresponding to fully adjusted 
births and deaths, and excluding the 6(2) females who out-married based on the estimates of out-marriage rates developed by Clatworthy (1994).

\section{Estimated Total Fertility Rates, 1974-1996}

Following the adjustment procedures outlined in the previous sections, total fertility rates for Registered Indians were developed for 1974 to 1996 . These TFRs were generated based on three-year averages of births for the years 1974 to 1995 . However, one-year data were used for $1996^{7}$. The TFR calculated as described showed a steady decline in the past 22 years, from 4.42 children per woman in 1974 to 2.73 in 1996, a decline of 1.69 children per woman (see Table 2 and Figure 3).

As a result of the steady fertility decline of Registered Indians in the past two decades, fertility levels of the Registered Indian and total Canadian populations have been converging. In 1976, the total fertility rates of Registered Indians was 3.95 children per woman, while that of the total Canadian population was 1.79, a difference of 2.16 children per woman. By 1996, the gap was reduced to 1.11 children per woman (see Table 2 and Figure 2).

\section{Summary and Concluding Comments}

Since the Indian Register was established mainly for administrative purposes and the Registered Indians have no incentives to register vital events promptly, data from the Register are subject to lengthy delays of vital events, omissions, and other anomalies. The demographic data of the Registered Indian population are, therefore, defective and require substantial adjustments in order to develop meaningful demographic indices. In order to construct fertility measures of Registered Indians, the time series data on births require data "cleaning" (corrections for coding inconsistencies, double counting, etc), adjustment for late reporting, and underreporting. In addition, the population data have to be adjusted for late reported and underreported births and deaths.

Before 1985, fertility rates could be derived once the birth and population data were adjusted for late reporting and underreporting of vital events. However, estimating the fertility level of Registered Indians became more complicated with the passing of the 1985 Amendments to the Indian Act (Bill C-31). These amendments contain new rules that govern entitlements to Indian registration for all children born to Registered Indians after April 17 of 1985. As a result, the Register data become of lesser quality for constructing fertility measures. The problem of an incompatible numerator and denominator occurs under two circumstances: children of parental combinations of 6(1) males and non-Indian females are entitled to be registered but their mothers are not on the Register; and children of 6(2) females and non-Indian males are not entitled to be 
Table 2

Total Fertility Rates for Registered Indians and Total Population for Canada, 1974 to 1996

\begin{tabular}{|c|c|c|}
\hline Year & $\begin{array}{c}\text { Registered } \\
\text { Indians }\end{array}$ & All Canadians \\
\hline 1974 & 4.42 & 1.88 \\
\hline 1975 & 4.16 & 1.81 \\
\hline 1976 & 3.95 & 1.79 \\
\hline 1977 & 3.74 & 1.76 \\
\hline 1978 & 3.62 & 1.71 \\
\hline 1979 & 3.52 & 1.70 \\
\hline 1980 & 3.41 & 1.69 \\
\hline 1981 & 3.33 & 1.66 \\
\hline 1982 & 3.33 & 1.64 \\
\hline 1983 & 3.29 & 1.62 \\
\hline 1984 & 3.27 & 1.62 \\
\hline 1985 & 3.24 & 1.61 \\
\hline 1986 & 3.18 & 1.59 \\
\hline 1987 & 3.03 & 1.57 \\
\hline 1988 & 2.92 & 1.60 \\
\hline 1989 & 2.86 & 1.65 \\
\hline 1990 & 2.83 & 1.71 \\
\hline 1991 & 2.85 & 1.71 \\
\hline 1992 & 2.87 & 1.71 \\
\hline 1993 & 2.86 & 1.68 \\
\hline 1994 & 2.80 & 1.68 \\
\hline 1995 & 2.76 & 1.67 \\
\hline 1996 & 2.73 & 1.62 \\
\hline
\end{tabular}

Source: Registered Indians: Rates calculated using data adjusted for late reporting and under-reporting of births and deaths; and taking into account the impact of the inheritance rules.

All Canadians: Statistics Canada, Demography Division, special tabulations. 
Figure 3

Total Fertility Rates for Registered Indians and Total Canadians, 1974 to 1996

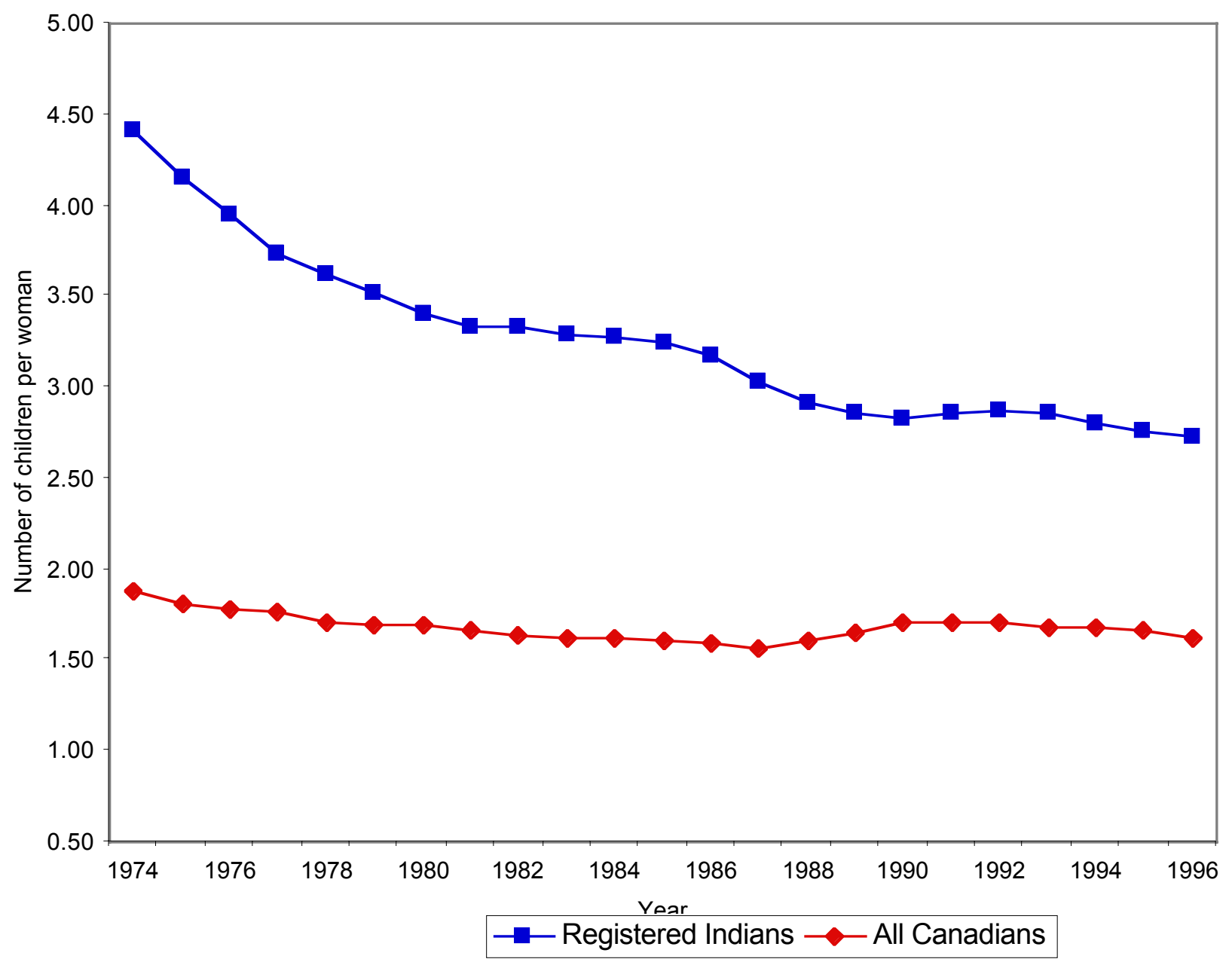


registered while their mothers are on the Register. In either case, the numerator and denominator will not be compatible. Using information on the out-marriage rates of 6(2) females, and the percentage of births resulting from the parental combination of a 6(1) Indian male and a non-Indian female, a compatible numerator and denominator were obtained in order to derive reliable fertility rates.

It is important to bear in mind that the reliability of the fertility rates presented depends on the procedures employed to adjust the time series on births and population data, as well as the underlying assumptions involved to take into account the impact of the inheritance rules. In order to monitor temporal changes in fertility rates, it is necessary to reassess the adjustment procedures and assumptions when more up-to-date information becomes available.

As noted earlier, before 1985, the major challenges in estimating the fertility level of the Registered Indians were "cleaning" data anomalies, and adjusting the data for late reporting, and underreporting of vital events. However, due to the inheritance rules introduced by the 1985 amendments to the Indian Act, the challenges tend to become greater as time passes. According to the inheritance rules, offsprings of Registered Indians are not entitled to Indian registration after two successive generations of out-marriage. Thus future size of the Registered Indian population in Canada will be affected by past and future rates of outmarriage. As a result of the inheritance rules, births to a 6(2) parent and a nonIndian will not be eligible for registration, which will be transferred to the nonRegistered Indian group, resulting in a population loss to the Registered Indian group. Due to the cumulative nature of the inheritance rules, an increasing percentage of Registered Indian births will be excluded in future years ${ }^{8}$. Understanding and interpreting the complex process of the inheritance rules and their impact on the number of Registered Indian births and on the Registered Indian female population, i.e., the numerator and denominator for the calculation, is a new challenge in estimating and analyzing the fertility level of Registered Indians.

\section{Acknowledgements:}

The French translation of the abstract by François Nault, and editorial comments by Ian Kisbee, Demography Division, Statistics Canada are gratefully acknowledged. The views expressed herein are those of the authors and do not necessarily reflect those of Statistics Canada. 


\section{Endnotes:}

1. Status Indians refer to Registered Indians.

2. The socio-economic indicators examined are: average total income of women 15 years and over, who reported income; average income of female lone-parent families; labour force participation of women 30-44 years old; women 15-29 years old with less than Grade 9; and average number of children ever-born per 1,000 ever-married women in age groups 15-19 and 20-24.

3. A lag is defined as the difference between the year of reporting and the year of occurrence of an event. Lag 0 indicates that the event is reported in the year of its occurrence; lag 1, one year later; lag 2, two years later; and so on.

4. Life expectancies at birth for Registered Indian males and females in 1981 were estimated to be 62.4 and 68.9 years, respectively. Life expectancy at birth for the total population of Canada in 1940-42 was 63.0 for males and 66.3 years for females.

5. The adjustments were carried out by the Population Projections Section of Statistics Canada under contract for DIAND to generate population projections for Registered Indians in Canada, 1996-2021.

6. Materials on the descent rules were taken from Clatworthy, 1994.

7. For the Yukon region, the 1996 TFR was estimated by taking the average of 1995 and 1996 births as the 1996 births were relatively few in number.

8. In the recent short-term population projections of Registered Indians, 1998 to 2008 , the number of births ineligible for registration is projected to increase from around 1,200 in 1999 to almost 1,800 by 2008 if the proportion of births not eligible for registration increases from around $9 \%$ in 1999 to $13 \%$ by 2008 , combined with an assumed moderate decline in fertility. 
Shirley Loh \& M. V. George

\section{References:}

Brass, W. 1968. "On the Scale of Mortality." In William Brass et al, The Demography of Tropical Africa. Princeton, New Jersey: Princeton University Press.

Clatworthy, S. 1994. Revised Projection Scenarios Concerning the Population Implications of Section 6 of the Indian Act. Four Directions Consulting Group, Winnipeg, Manitoba.

Loh, S., R.B.P. Verma, E. Ng, M.J. Norris, M.V. George and J. Perreault. 1998. Population Projections of Registered Indians, 1996-2021. Report prepared by Population Projections Section, Demography Division, Statistics Canada for the Department of Indian Affairs and Northern Development.

Loh, S. 1997a. Preliminary Report on Births Time Series Adjustment for Registered Indian Population, Canada, 1972 to 1996. Report prepared by the Population Projections Section, Demography Division, Statistics Canada for the Department of Indian Affairs and Northern Development.

Loh, S. 1997b. Progress Report on Estimating Total Fertility Rates for Registered Indians, 1974-1996 and Projecting the Rates to 2021. Report prepared by the Population Projections Section, Demography Division, Statistics Canada for the Department of Indian Affairs and Northern Development.

Loh, S. 1990. Population Projections of Registered Indians, 1986-2011. Report prepared by the Population Projections Section, Demography Division, Statistics Canada for Indian and Northern Affairs Canada.

Nault, F., J. Chen, M.V. George and M.J. Norris. 1993. Population Projections of Registered Indians, 1991-2015. Report prepared by the Population Projections Section, Demography Division, Statistics Canada for Indian and Northern Affairs Canada.

Nault, F., J. Chen and M.J. Norris. 1992. Demographic Time Series Data on Births, Deaths, and Population for Registered Indian Population, Canada, 1973-1990. Report prepared by the Population Projections Section, Demography Division, Statistics Canada for Indian and Northern Affairs Canada. 
Perreault, J., L. Paquette and M.V. George. 1985. Population Projections of Registered Indians, 1982 to 1996. Report prepared by the Population Projections Section, Demography Division, Statistics Canada for Indian and Northern Affairs Canada.

Piché, V. and M.V. George. 1973. "Estimates of Vital Rates for the Canadian Indians, 1960-1970," Demography, 10(3): 367-382.

Ram, B. 1991. Assimilation and Fertility of Native Indians: Some New Evidence. Paper presented at the annual meeting of the Canadian Population Society, Kingston, Ontario, June, 1991.

Ram, B. and A. Romaniuc. 1985. Fertility Projections of Registered Indians, 1982-1996. Report prepared by the Population Projections Section, Demography Division, Statistics Canada for Indian and Northern Affairs Canada.

Romaniuc, A. 1993. Fertility Transition among Canadian Aboriginal Population: A Theoretical Perspective. Ottawa, Ontario: Statistics Canada.

Romaniuc, A. 1992. Emergence of Modern Low Fertility Patterns among Aboriginals in Canada - An Exploration into Underlying Processes. Paper presented at the Conference on the Peopling of the Americas, Veracruz, Mexico, May, 1992.

Romaniuc, A. 1987. "Transition from Traditional High to Modern Low Fertility: Canadian Aboriginals," Canadian Studies in Population, 14(1): 69-88. 